\title{
THE EFFECTS OF INSULIN LIKE GROWTH FACTOR-1 AND ERITHROPOETIN ON APOPTOSIS AND TELOMERASE ACTIVITY IN AN EXPERIMENTAL NECROTIZING ENTEROCOLITIS MODEL
}

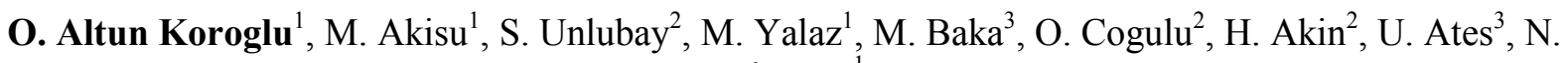 \\ Kultursay ${ }^{1}$ \\ ${ }^{I}$ Neonatology, ${ }^{2}$ Medical Genetics, ${ }^{3}$ Histology and Embryology, Ege University, Izmir, Turkey
}

Background and aims: Apoptosis, that occurs after hypoxia/reoxygenation (H/R), has an important role in the pathogenesis of necrotizing enterocolitis (NEC) which is a major cause of morbidity and mortality in premature infants. Telomerase activity, showing the regenaration capacity, may also be important in the recovery process. We aimed to see the effects of insulin-like growth factor-1 (IGF) and erithropoetin (EPO) on apoptosis and telomerase activity in a H/R model .

Methods: Young mice were divided into 4 groups ( $\mathrm{n}=10 /$ group): group 1 mice $(\mathrm{H} / \mathrm{R})$ were exposed to H/R; group $2(\mathrm{H} / \mathrm{R}+\mathrm{IGF}-\mathrm{I})$ \& group $3(\mathrm{H} / \mathrm{R}+\mathrm{EPO})$ mice were pre-treated with IGF-1 and EPO respectively, for 7 days before H/R. Group 4 served as control. Intestinal injury was evaluated by histological scoring and assesment of apoptosis by TUNEL test. Pro-apoptotic (p53, caspase3, TNF, Bax, FAS, Bad) and antiapoptotic (Bcl2, Bcl-w, Bcl-XL, NF-kappa B) gene expressions, and telomerase activity were studied by real time PCR.

Results: IGF-1 and EPO treated animals had decreased histological damage and apoptosis confirmed by TUNEL test and caspase activity. Telomerase activity was increased in these animals in addition to increased expression of anti-apoptotic genes such as BCL-2, BCL-W, BCL-XL $(p<0.01)$. However pro-apoptotic gene expressions (TERT, GAPDH, P53, STAT3, TNF-alfa, FAS, ACTB, BAX) were not different (p>0.05).

Conclusion: The protective effects of IGF-1 and EPO in H/R damage may be through increased expression of anti-apoptotic genes.

Acknowledgement: This study was supported by TÜBİTAK (The Scientific and Technical Research Council of Turkey), grant 107S397. 